\title{
Interactive comment on "Evaluating the streamflow simulation capability of PERSIANN-CDR daily rainfall products in two river basins on the Tibetan Plateau" by Xiaomang Liu et al.
}

\section{Anonymous Referee \#2}

Received and published: 8 November 2016

In this manuscript, authors presented an application of a precipitation estimate product based on satellite (PERSIANN-CDR) on gauge-sparse area, in which the accuracy of PERSIANN-CDR on two river basins on the Tibet Plataea of China are evaluated in terms of the simulated streamflow using a conceptual hydrological model. In the two river basins, gauge or radar information is limited in mountainous area due to their distribution, coverage, and beam angle. Therefore, satellite information will be good alternative than other sources of information. Before practical uses, verification is needed so that decision makers and local agency can have certain level of confidence which source of information is the most reliable. The contributions of this paper are 
two in reviewer's opinion: (1) it evaluates a recent develop long-term global precipitation dataset against gauge, and GLADAS (in the revised version attached to AC2), and demonstrates the accuracy of streamflow simulation for the three sources of information. (2) the provides a way of utilizing streamflow to verify precipitation products, since streamflow is more reliable in mountainous area. The approach author took in this manuscript can be applied in other gauge-limited area for verification study.

Interactive

As mentioned by anonymous referee 1 and short comment reviewer, the comparison with other source of precipitation data will be beneficial to improve the manuscript. After all, the sore comparison between satellite precipitation with limited gauge network via streamflow cannot fully support the conclusion of satellite information is better than limited gauge network for the two river basins on TP. Adding other source of information, such as GLADAS, could be considered as a more comprehensive study. In addition, the frozen soil issue is common in conceptual hydrological model, regardless whether the model is distributed, semi-distributed, lump. However, this does not undermine the approach that authors are trying to propose and the message authors want to delivery. If using land-surface models instead of hydrological models, that will be another study that is out of the scope of this study. Last, reviewer think the length of data is very crucial in simulating the streamflow. As authors did in discussion, different lengths of calibration data are used to study the sensitivity of data. It is suggested that authors also mention this in the context that besides the accuracy of data, the length is also important.

In general, I noted that this manuscript has already been revised from its original submission through the a several open discussion processes. The comments given by anonymous reviewer 1 and short comment reviewer in previous open discussion phases are suggestive and important. I agree with anonymous referee 1 and short comment (SC) reviewer that the original submission suffered from not addressing those key points, including the evaporation, comparison with GLADAS precipitation, frozen soil issue, and some minor language issues. By comparing the original submission and

Printer-friendly version

Discussion paper 
the revised version attached to authors' reply to SC1, I think the authors did a good job in addressing previous comments: the comparison of GLADAS is added, the evaporation and frozen soil issues are discussed since they are key element in TP area, and the presentation (grammar) has been improved.

Therefore, I think the revised version is suitable for prompt publication. The following are only minor editing issues that can be fixed in proof-reading or revise phase. (Line numbers refer to the revised version attached to AC2).

Line 42: "potential to be a reliable"

Line 97: missing "the" before United State

Line 99: "show"

Line 108: add "the" before "limited" and "precipitation"

Line: 110: "capabilities"

Line: 120: "relatively"

Line 122: CMORPH "start"

Line 253: "Hydrometeorology"

Line 350: replace "both" with "all"

Line 423: insert "a" before "previous study"

Line 480: "using only"

Line 510: replace "both" with "all"

Line 512: "have" Line 515: could "not be" fully Line 527: product "has" Line 528: insert "an" before alternative Line 528: replace "for" with "in"

Interactive comment on Hydrol. Earth Syst. Sci. Discuss., doi:10.5194/hess-2016-282, 2016. 